\title{
Nuclear Medicine in Nottingham: Antibodies, Gamma Probes and Drug Delivery
}

\author{
Alan C. Perkins
}

When I started work in Nottingham in 1980 University Hospital had only recently been built. The University of Nottingham Medical School and Hospital was officially opened by the Queen on 28 July 1977 and named 'Queen's Medical Centre'. At the time it was completed it was to be one of the biggest hospitals in Europe with over 1300 beds and 27 miles of corridor. The nuclear medicine department was equipped with a Siemens single head camera and was the first out patient department in the hospital to receive patients. This was one of three hospitals in Nottingham where nuclear medicine was undertaken, the other two being Nottingham City Hospital and the Nottingham General Hospital near Standard Hill, (named after the point where King Charles raised his Royal Standard in 1642, thus starting the English Civil War). In the early 1980s the General Hospital was still carrying out nuclear medicine scans on a rather old rectilinear scanner. When this facility was closed nuclear medicine was further developed at both Queen's Medical Centre and the Nottingham City Hospital. With the Medical School still being in its infancy there were many young clinical and scientific staff eager to make an impact and many diverse areas of research developed that involved nuclear medicine techniques.

The Cancer Research Laboratories at Nottingham University were a collection of old single story huts on the university site now occupied by the Biomedical Sciences Building, on the opposite side of the ring road to the Medical School. In the early 1980s Professor Robert Baldwin lead a team of 50 scientists who were developing the then new monoclonal antibody technology. Along with the University of Birmingham, and the Charring Cross Hospital, London, Nottingham pioneered the

\footnotetext{
A.C. Perkins

Department of Radiological Sciences, University of Nottingham, Nottingham, UK

Radiological Sciences, Nottingham University Hospitals NHS Trust, Nottingham, UK 

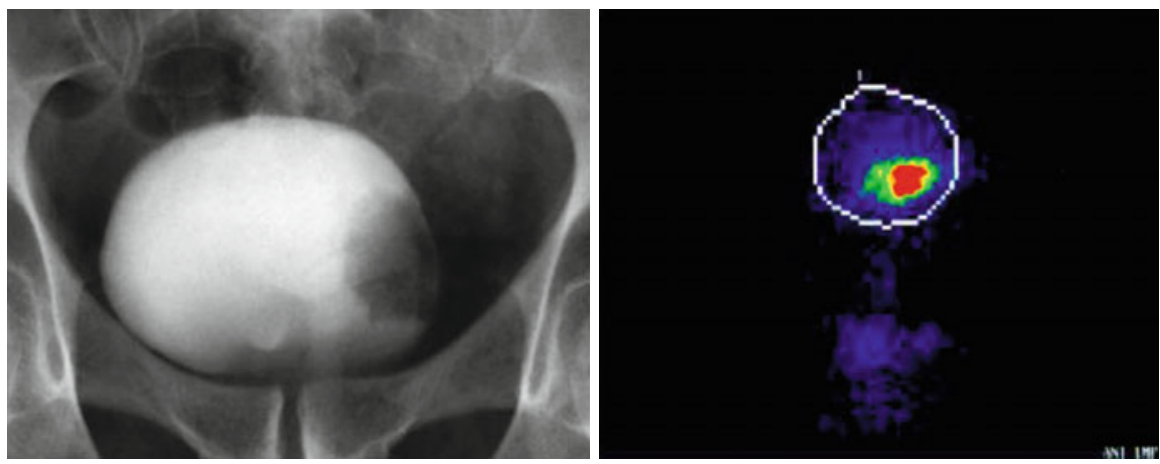

Fig. 13.1 An intravenous urogram and ${ }^{67} \mathrm{Cu}-\mathrm{C} 595$ image in a patient with a superficial cancer of the bladder

in vivo use of monoclonal antibody imaging. One of the first antibodies to be used was 791t/36 produced from a patient with osteogenic sarcoma. The first clinical use of this antibody was carried out in patients with colorectal cancer [1]. The imaging was technically demanding since the first antibodies were radiolabelled with I-131 and the long survival of the antibody in the circulation necessitated the use of background subtraction employing Tc-99m-labelled human serum albumin [2]. The work with monoclonal antibodies progressed with Nottingham undertaking some of the first in vivo studies using In-111 and Tc-99m-labelled antibodies [3, 4] and published one of the first studies of SPECT antibody imaging [5]. Work with antibody fragments (Fab and $\mathrm{F}\left(\mathrm{ab} \mathrm{b}^{\prime}\right) 2$ ) progressed and over the next 10 years the affects of antibody responses were observed leading to a decline in routine use. Therapeutic trials of $\mathrm{Cu}-67-\mathrm{C} 595$ anti-MUC1 antibody in bladder cancer continued and this approach still offers unexplored potential Fig. 13.1 [6]. The European directives on the GMP conditions required for the production of biologicals including antibodies, meant that the Nottingham production facilities were no longer suitable for the manufacture of clinical grade materials and so the "home grown" antibody studies came to an end.

Other work in Nottingham led the way for the early use of intraoperative probes for the detection of lesions removed during surgery. Work started by John Hardy with one of the orthopaedic surgeons, Chris Colton in Nottingham led to the use of the gamma probe for the localization of osteoid osteoma Fig. 13.2 [7].

This pre-dated the use of gamma probes for sentinel node detection and led to the development of the RMD gamma probe in the United States. Over a period of 10 years I personally travelled from Southampton to Aberdeen assisting surgeons localize a variety of lesions $[7,8]$. Similar techniques were developed for the use of probes in the intensive care unit [9].

Over the past 30 years Nottingham has been associated with other areas of nuclear medicine research. Working with Malcolm Frier a range of novel radiopharmaceutical products were developed and investigated including recombinant human 


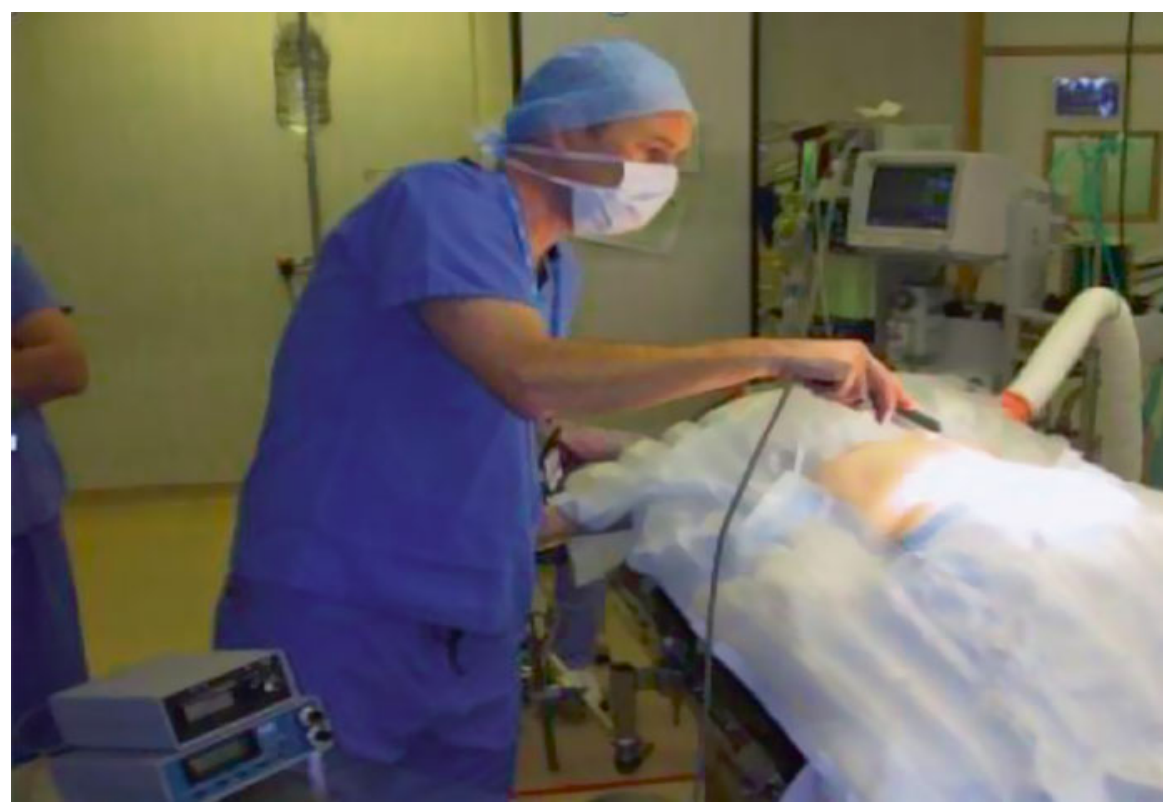

Fig. 13.2 The author using an early gamma probe in the operating theatre in the 1980 s

serum albumin [10] a spin off from the Bass brewing industry and recombinant branched-chain polypeptide synthetics [11] and aptamers [12]. Perhaps more unique to Nottingham was the use of nuclear medicine techniques in the study of conventional drug delivery and formulation. Extensive studies were undertaken to image the release, delivery and biodistribution of formulations including enteric coated oral dose forms, enemas, eye drops, nasal sprays and aerosols [13-15]. Much of this work has involved the study of tablet swallowing [16], gastrointestinal transit, the understanding of gastrointestinal physiology and the development of nuclear medicine imaging techniques for the study of the gastrointestinal tract Fig. 13.3 [17].

These areas of work have continued with the application of magnetic resonance imaging in the study of gastrointestinal transit [18, 19].

More recently through a collaboration with John Lees at the Space Research Centre at Leicester University, Nottingham has been pioneering the first clinical use of a hand-held hybrid optical gamma camera for small parts imaging and for use in intraoperative imaging Fig. 13.4 [20]. Studies are continuing in collaboration with surgeons in Nottingham and Derby.

Acknowledgements I would like to express my appreciation to some of the many colleagues who I have worked with in Nottingham and who have helped in my career over the past 35 years. These include John Hardy, Jack Hardcastle, Clive Wilson, Bob Davies, Malcolm Pimm, Mike Price, Malcolm Symonds, Malcolm Frier, Colin Barber, Martin Wastie and John Lees. 


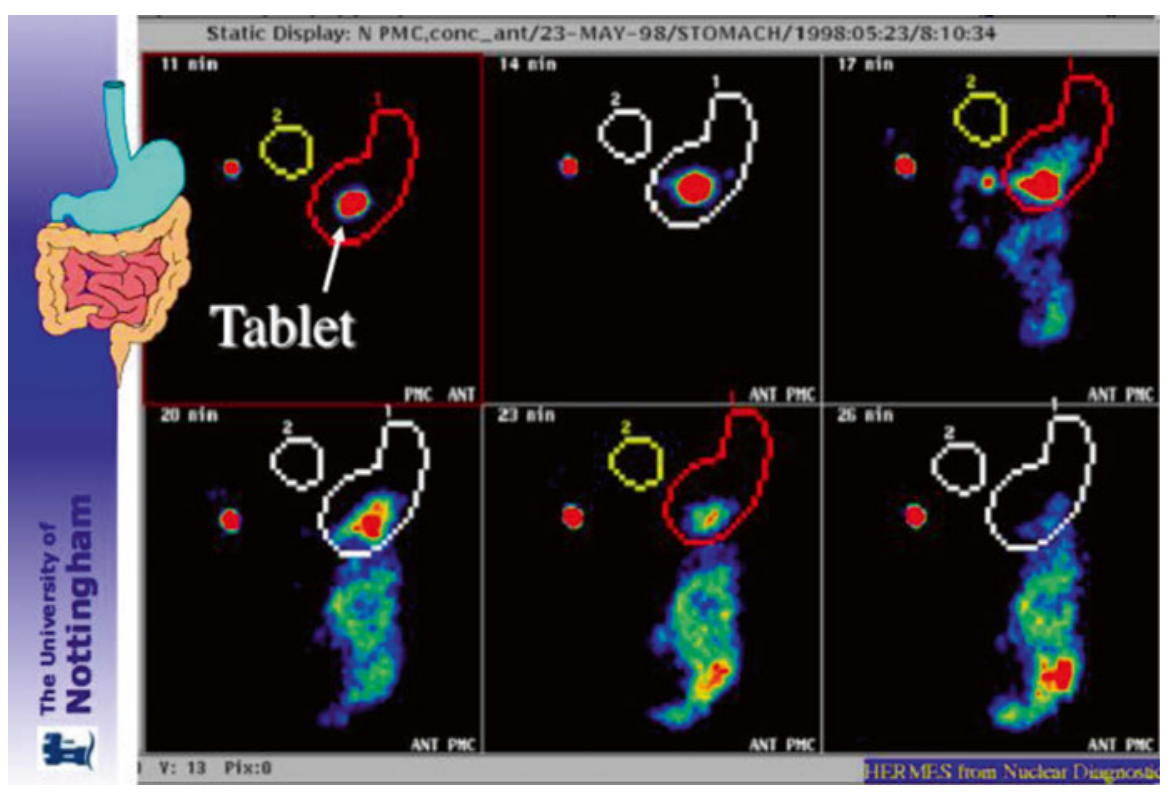

Fig. 13.3 Shows the process of a tablet in the stomach disintegrating and emptying into the small bowel

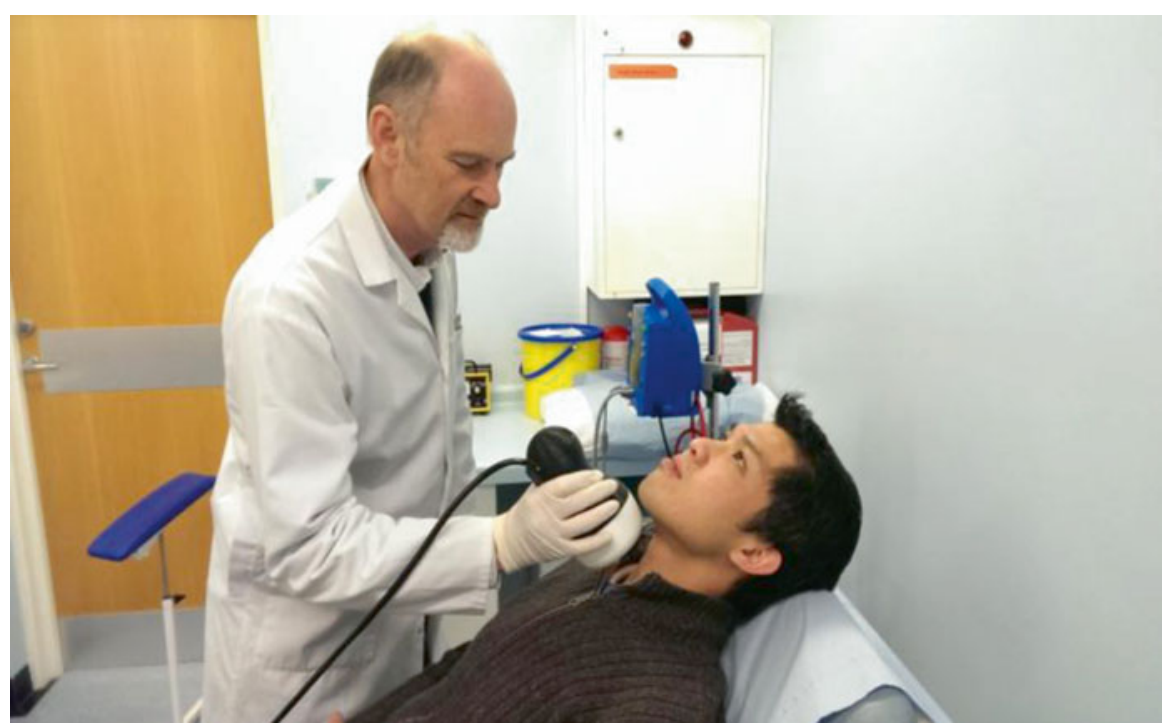

Fig. 13.4 A hand held intraoperative hybrid optical gamma camera 
Open Access This chapter is distributed under the terms of the Creative Commons AttributionNoncommercial 2.5 License (http://creativecommons.org/licenses/by-nc/2.5/) which permits any noncommercial use, distribution, and reproduction in any medium, provided the original author(s) and source are credited.

The images or other third party material in this chapter are included in the work's Creative Commons license, unless indicated otherwise in the credit line; if such material is not included in the work's Creative Commons license and the respective action is not permitted by statutory regulation, users will need to obtain permission from the license holder to duplicate, adapt or reproduce the material.

\section{References}

1. Farrands PA, Perkins AC, Pimm MV, Hardy JG, Baldwin RW, Hardcastle JD. Radioimmunodetection of human colorectal cancers using an anti-tumour monoclonal antibody. Lancet. 1982;II:397-400.

2. Perkins AC, Whalley DR, Hardy JG. Physical approach for the reduction of dual radionuclide image subtraction artefacts in immunoscintigraphy. Nucl Med Commun. 1984;5:501-12.

3. Perkins AC, Pimm MV, Birch MK. The preparation and characterisation of In-111-labelled 791T/36 monoclonal antibody for tumour immunoscintigraphy. Eur J Nucl Med. 1985;10:296-301.

4. Pimm MV, Perkins AC, Baldwin RW. Labelling of monoclonal antibody with metallic radionuclides: preparation of antibody-DTPA conjugates from DTPA anhydride in organic solvent. ICRS Med Sci. 1986;14:104-5.

5. Perkins AC, Whalley DR, Ballantyne KC, Pimm MV. Gamma camera emission tomography using radiolabelled antibodies. Eur J Nucl Med. 1988;14:45-9.

6. Hughes ODM, Bishop MC, Perkins AC, Wastie ML, Denton G, Price MR, Frier M, Denley H, Rutherford R, Scubiger PA. Targeting superficial bladder cancer by the intravesical administration of Cu-67-labelled anti-MUC1 mucin monoclonal antibody. J Clin Oncol. 2000;18:363-70.

7. Perkins AC, Hardy JG. Intra-operative nuclear medicine in surgical practice. Nucl Med Commun. 1996;17:1006-15.

8. Aslam A, Perkins AC, Spicer RD. Peroperative I-123-MIBG scan using a sterile probe for staging and resection of neuroblastoma in children. J Pediatr Surg. 1996;5:719-20.

9. Perkins AC, Yeoman P, Hindle AJ, Vincent RM, Frier M, Winter RJ, Wastie ML. Bedside nuclear medicine investigations in the intensive care unit. Nucl Med Commun. 1997;18:262-8.

10. Perkins AC, Frier M. Experimental biodistribution studies of Tc-99m-recombinant human serum albumin (rHSA); a new generation of radiopharmaceutical. Eur J Nucl Med. 1994;21:1231-3.

11. Perkins AC, Frier M, Pimm MV, Hudecz F. Tc-99m-branched-chain polypeptide (BCP): a potential synthetic radiopharmaceutical. J Labelled Compounds Radiopharm. 1998;XLI:631-8.

12. Perkins AC, Missailidis S. Radiolabelled aptamers for tumour imaging and therapy. Q J Nucl Med Mol Imaging. 2007;51:1-5.

13. Perkins AC, Pimm MV, Wilson CG. Gamma scintigraphy in the delivery, biodistribution and targeting of therapeutic agents. J Nucl Biol Med. 1994;38(Suppl 1 to No 4):113-8.

14. Perkins AC, Frier M. Nuclear medicine in pharmaceutical research. London: Taylor and Francis; 1999.

15. Perkins AC, Frier M. Radionuclide imaging in drug development. Curr Pharm Design. 2004;10:2907-21.

16. Frier M, Perkins AC. Radiopharmaceuticals and the gastrointestinal tract. Eur J Nucl Med. 1994;21:1234-42.

17. Perkins AC, Blackshaw PE, Hay PD, Lawes SC, Atherton CT, Dansereau RJ, Wagner LK, Schnell DJ, Spiller RC. Esophageal transit and in vivo disintegration of generic alendronate tablets and branded Risedronate tablets: a single-center, single-blind, six-period crossover study in 20 healthy female subjects. Clin Ther. 2008;30:834-44. 
18. Yeong CH, Abdullah BJJ, K-H NG, Chung L-Y, Goh K-L, Perkins AC. Fusion of gamma scintigraphic and MR images improves the anatomical delineation of radiotracer for the assessment of gastrointestinal transit. Nucl Med Commun. 2013;34:645-51.

19. Chaddock G, Lam C, Hoad CL, Costigan C, Cox EF, Placidi E, Thexton I, Wright J, Blackshaw PE, Perkins AC, Marciani L, Gowland PA, Spiller RC. Novel MRI tests of orocecal transit time and whole gut transit time: studies in normal subjects. Neurogastroenterol Motil. 2014;26(2):205-14.

20. Lees JE, Bassford DJ, Blake OE, Blackshaw PE, Perkins AC. A hybrid camera for simultaneous imaging of gamma and optical photons. J IINST. 2012. doi:10.1088/1748-0221/7/06/P06009. 


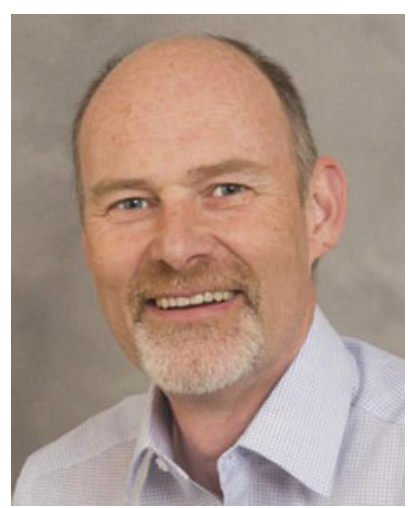

\begin{abstract}
Alan Perkins After completing an MSc in Medical Physics at the University of Leeds in 1979 I started work in Medical Physics at Queen's Medical Centre, Nottingham, where I undertook a PhD in Monoclonal Antibody Imaging in the department of Surgery in the Medical School at the University of Nottingham from 1983 to 1986. After a period heading up Nuclear Medicine and Radiation Protection in the hospital department I took up a university post as Reader in Medical Physics and was appointed to Clinical Professor in 1999. I was awarded Fellow of the Institute of Physics and Engineering in Medicine in 1990, Fellow of the Royal College of Radiologists, in 2008 and an honorary Fellow of the Royal College of Physicians of London in 2011. During my time as President of the British Nuclear Medicine Society I helped establish the society offices to their current location at the Nottingham University Innovation Park.
\end{abstract}

